\title{
Hierarchy: A Key Idea for Business and Society
}

John Child, London, Routledge, 2019, pp150 ISBN 978-1-138-04441-8

Hierarchy, John Child states in his new book, 'deserves more attention'. It plays a central role in our lives, he argues, structuring virtually all organizations through which we live and work, yet hierarchy is widely neglected in academic work. A key reasons for this lack of attention, Child contends, is that hierarchy is often seen as inevitable, natural, and is thus taken-for-granted. Consequently we have accepted and internalised it, and do not see it for what it is. This short book, a mere 150 pages asks us to look more closely at hierarchy.

Chapter 2 offers a tour de force of key philosophical and theological readings of hierarchy from the Greek (particularly Plato), Religious (Islamic, Confucius, Christian and Hindu traditions) through to Management Thinking (primarily scientific management justification for managerial hierarchy). Drawing these traditions together Child examines the conditions under which hierarchy arises, the basis of justifications of hierarchy authority, and how to deal with potential abuses of hierarchy. These inevitably abstract accounts are interesting and provides the basis of a core claims Child makes, that hierarchy can have significant social good, providing it is not for personal aggrandizement.

Chapter 3 moves into examining the more 'evidence based' human and social sciences. Providing an account which would be largely familiar to scholars of management and organizational studies, ideas from biology and genetics, psychology, anthropology, sociology and political science are explored from views where hierarchy is natural (biology and genetics, and psychology) through to being socially constructed in anthropology, sociology and political science. Utilizing this literature allows Child to examine how hierarchy has be debated within business and management, and the underlying logics that inform these debates.

Chapter 4 examines why organizational hierarchy has been so persistent, despite Tom Peters and other 'gurus' announcing, somewhat premature, its death. One of the interesting arguments here is when there was a reduction of formal hierarchies this brought an increase in informal hierarchies, particularly through the internalization of corporate culture.

Furthermore, attempts at flattening the organization, such as delayering and downsizing often come with increased targets which perversely 'reinforce hierarchical command and control' (p68). Moreover, concern over CSR and the prevention of corporate scandals has meant that more devolved and networked organizations have fewer clear lines of accountability and thus make organizations more vulnerable in cases of abuse. The remainder of the chapter focuses on what people can get from hierarchy, including personal career and psychological benefits. The argument emerges here, and is a key part of the idea that Child puts forward towards the end of the book, is that hierarchy should not be ditch altogether, but we need enough hierarchy to do the key roles, provide strategic direction, coordination and provide the psychological benefits, in order to function well. Yet, hierarchy needs reforming.

Chapter 5 looks at the costs of hierarchy, including financial (management as a tax on a business), communication distortion, impacts on innovation and the internal disfunctions which can arise. The social costs, of wealth inequality (CEO pay and the impact it has on society), as well as the lack of opportunities for personal growth and development for those 
lower down the hierarchy are presented as core costs. This overview provides a good account of the problems of hierarchy. The problem it seems is where there is an excess of hierarchy.

The final two chapters present the case for reform. Chapter 6 provides a rather brief further account of the problems of hierarchy, this time linking them to larger societal issues such as the Me Too movement and wider social powerlessness than many people experience when they feel those in power do not listen to them. In Chapter 7 Child lays out the case for reform. This is not a book advocating the rejection of hierarchy, rather, in line with some of the arguments put forward earlier in the book, he argues for retaining the benefits of hierarchy (particularly for large-scale organizations) but ameliorating the downsides. A series of reforms are offered including some delayering (although this should be treated with caution), redefinition of roles and support of teamwork, all to promote some forms of selfmanagement, but with the caveat that this will be limited in large-scale organizations. Behavioural reform to build trust is also another part of the equation as well as making hierarchical leadership more accountable. Ideas put forward include forms of employee ownership (though share schemes) and employee representation as well as systems to hold management to account.

This is a nicely written and extremely well-structured book that provides an excellent introduction to anyone wanting a clear and concise overview of organizational hierarchy, presenting some complex themes in an erudite manner. However there is a tendency to rely heavily on classic texts, arguably at the exclusion of recent developments in the field, which is a shame as some of these more recent experiments that are seeking to explore new ways of working without hierarchy or new forms of hierarchy are largely ignored in this book.

One of the reasons or consequences of this somewhat narrow take is that Child takes an (explicitly) reformist view. Indeed, it is quite fitting, given the general tone of the argument that he puts forward, that the book ends with John Lewis, the UK retail store to be presented as the example of how things could be. John Lewis, founded as a response to the perceived threat of revolution, takes a very much a reformist view on worker involvement, with largely paternalistic structure with little direct role for employees and arguably privileges managerial interest (Paranque \& Willmott, 2014).

A potentially more radical take on the question of hierarchy could have examined forms of self-management, or worker cooperatives, such as Mondragon, Occupy!, new social movement, anarchist organizations or the recuperated factories, or also the challenges of trying to bring in less hierarchical ways of organizing, and various other experiments in horizontal forms of organizing (Bretos \& Errasti, 2017; King \& Land, 2018). There is a brief foray into Zappos' attempts to engage with Holacracy, but beyond this somewhat short look there is little other discussion of other more radical alternatives. Similarly there is little account of hierarchy and gender which has been widely developed within organizational studies. An anarchist reading of hierarchy could have provided a rather more fundament platform for the critique of hierarchy (Swann \& Stoborod, 2014). Alternatively new organizational practices, such as Sociocracy, could have offered alternative ways of retaining some of the perceived benefits of hierarchy, but structured in ways that might enable more democratic forms of participation in a more radical manner.

Daniel King, Nottingham Trent University 


\section{References}

Bretos, I., \& Errasti, A. (2017). Challenges and opportunities for the regeneration of multinational worker cooperatives: Lessons from the Mondragon Corporation-a case study of the Fagor Ederlan Group. Organization, 24(2), 154-173.

King, D., \& Land, C. (2018). The democratic rejection of democracy: Performative failure and the limits of critical performativity in an organizational change project. Human Relations, 71(11), 1535-1557.

Paranque, B., \& Willmott, H. (2014). Cooperatives-saviours or gravediggers of capitalism? Critical performativity and the John Lewis Partnership. Organization, 21(5), 604-625.

Swann, T., \& Stoborod, K. (2014). Did you hear the one about the anarchist manager? Ephemera: Theory \& Politics in Organization, 14(4), 591-609. 